\title{
PEMANFAATAN BROSUR SEBAGAI MEDIA PROMOSI UNTUK MENINGKATKAN JUMLAH PESERTA DIDIK PADA DUTA ISLAMIC SCHOOL (DIS) SEMARANG
}

\author{
Haryo Kusumo \\ Sekolah Tinggi Elektronika dan Komputer \\ haryo@stekom.ac.id
}

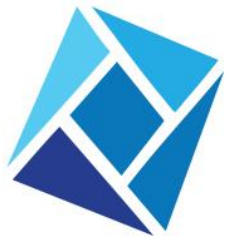

Jurnal Nusantara Aplikasi Manajemen Bisnis

http://ojs.unpkediri.ac.id/index. php/manajemen/index

E-ISSN : 2528-0929

P-ISSN : 2549 - 5291

Diterima: 08 Februari 2018

Revisi : 26 Maret 2018

Disetujui: 18 April 2018

https:doi.org10.29407nusamba.

v3i1.11916

\section{Abstract}

Duta Islamic School (DIS) Semarang is a business that is engaged in education of preschoolers. The absence of promotion within the DIS leads to a lack of awareness amongst the public. Duta Islamic School tries to attract people by making brochures as marketing and promotion media. In the application of brochure design is very unlimited because it is mass. This type of marketing and promotional media is also very effective in attracting consumers, usually containing fairly complete data with supporting images. Especially with an interesting design and creative. With the media marketing and promotion of brochures are expected to increase awareness among the community as well as to increase the number of learners at DIS.

Keywords: brochures, marketing media, promotion.

Abstrak

Duta Islamic School (DIS) Semarang merupakan sebuah usaha yang bergerak dibidang pendidikan anak prasekolah. Belum adanya promosi di dalam DIS menyebabkan kurangnya awareness dikalangan masyarakat. Duta Islamic School berusaha menarik minat masyarakat dengan membuat brosur sebagai media pemasaran dan promosi. Dalam penerapannya penggarapan desain brosur sangat tidak terbatas karenabersifat masal. Jenis media pemasaran dan promosi ini juga sangat efektif dalam menarik konsumen, biasanya memuat data yang cukup lengkap disertai gambar - gambar pendukung. Apalagi dengan desain yang menarik dan kreatif. Dengan adanya media pemasaran dan promosi brosur diharapkan dapat meningkatkan awareness dikalangan masyarakat sekaligus dapat meningkatkan jumlah peserta didik pada DIS.

Kata kunci : brosur, media pemasaran, promosi 


\section{A. Pendahuluan}

Pendidikan anak usia dini merupakan wahana pendidikan yang fundamental dalam memberikan kerangka dasar terbentuk dan berkembangnya dasar-dasar pengetahuan, sikap dan keterampilan pada anak. Hal ini berarti bahwa setiap program yang terkait dengan pembelajaran anak usia dini perlu mendapat perhatian (Mukminin, 2017)

Duta Islamic School (DIS) Semarang merupakan sebuah usaha yang bergerak dibidang pendidikan prasekolah. Belum adanya promosi di dalam DIS menyebabkan kurangnya awareness dikalangan masyarakat. Duta Islamic School berusaha menarik minat masyarakat dengan membuat brosur sebagai media pemasaran dan promosi. Dalam penerapannya penggarapan desain brosur sangat tidak terbatas karena bersifat masal. Jenis media pemasaran dan promosi ini juga sangat efektif dalam menarik konsumen, biasanya memuat data yang cukup lengkap disertai gambar - gambar pendukung. Apalagi dengan desain yang menarik dan kreatif. Dengan adanya media pemasaran dan promosi brosur diharapkan dapat meningkatkan awarenessdikalanganmasyarakat dengan cakupan yang lebih luas sekaligus dapat meningkatkan jumlah peserta didik pada DIS.

\section{B. Tujuan Penelitian}

Merancang dan membuat brosur DIS sebagai media pemasaran dan promosi yang efektif dan komunikatifuntuk meningkatkan jumlah peserta didik.

\section{Kerangka Pemikiran}

Berikut kerangka pemikiran yang menjadi landasan perencanaan brosur DIS.

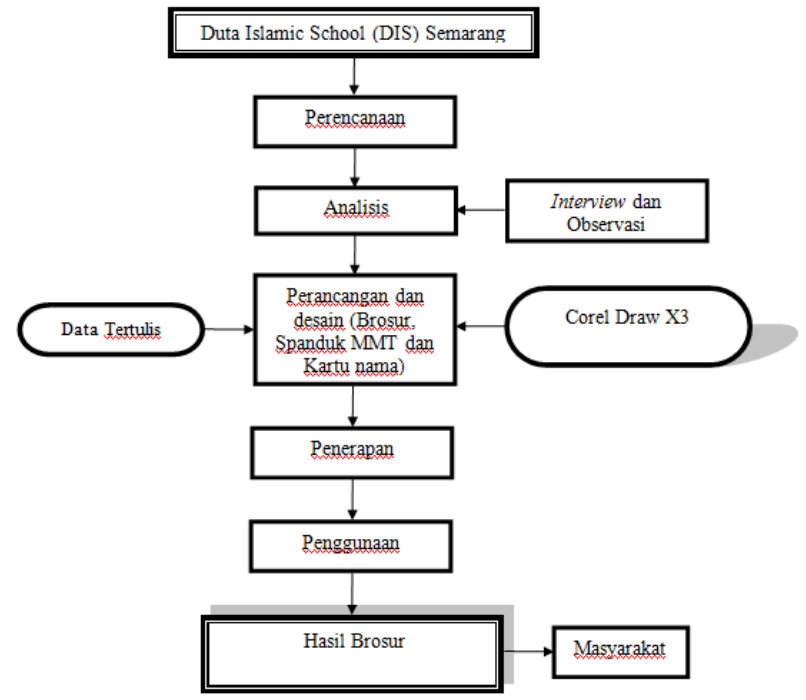

Gbr 1. Kerangka pemikiran

\section{Tinjauan Pustaka}

\section{Media}

Media berasal dari bahasa latin medius yang secara harfiah berarti tengah atau perantara atau pengantar. Media juga dapatmengantarkan sebuah informasi antara sumber dan penerima (Arsyad, 2002).

\section{Pemasaran}

Menurut Kottler \& Keller(2006)pemasaran adalah suatu proses kemasyarakatan yang melibatkan individu- individu dan kelompok untuk mendapatkan apa yang mereka butuhkan dan 
inginkan melalui penciptaan, penawaran, dan pertukaran secara bebas produk dan jasa nilai dengan pihak lain.

\section{Promosi}

Promosi merupakan usaha suatu perusahaan untuk mengkoordinasikan media -media informasi dan persuasi untuk memperkenalkan serta menjual produk, jasa, atau ide mereka (Belch \& Belch, 2004). Di sini komunikasi memiliki peran yang cukup penting. Komunikasi adalah alat unik yang digunakan pemasar untuk mempersuasi konsumen agar bertindak sesuai dengan harapannya seperti mengunjungi sebuah toko retail, memilih, melakukan pembelian. Pada konteks pemasaran, komunikasi yang digunakan dalam kegiatan pemasaran merupakan usaha yang terorganisir untuk mempengaruhi dan meyakinkan para pelanggan agar membuat pilihan -pilihan yang cocok dengan keinginan komunikator pemasaran serta sejalan dengan pemuasan kebutuhan pelanggan. Singkatnya komunikasi, dalam hal ini komunikasi pemasaran, adalah jembatan antara pemasar dengan konsumen dan antara konsumen dengan lingkungan sosial budayanya.

\section{Anak Prasekolah}

Menurut Biechler dan Snowman (1993), sebagaimana dikutip oleh Soemiarti Patmonodewo, mengatakan bahwa :

Anak prasekolah adalah mereka yang berusia antara 3-6 tahun. Mereka biasanya mengikuti program prasekolah. Sedangkan di Indonesia, umumnya mereka mengikuti program tempat penitipan anak (3 bulan - 5 tahun) dan kelompok bermain (usia 3 tahun), sedangkan pada usia 4-6 tahun biasanya mereka mengikuti program taman kanak-kanak.

\section{Brosur}

Andi (2005) menyatakan bahwa brosur adalah salah satu bentuk media yang digunakan untuk menyampaikan pesan yang cukup banyak dan detail, biasanya bersifat promotif. Sekolah - sekolah, rumah sakit, bimbingan belajar, penjualan komputer, dll, adalah lembaga yang kerap menggunakan media ini. Dalam penerapannya, penggarapan desain brosur sangat tidak terbatas karena bersifat masal.

5. Corel draw

Muliawan (2008) menyatakan bahwa Corel Draw adalah editor grafik vektor yang dibuat oleh Corel, sebuah perusahaan yang bermarkas di Ottawa, Kanada.

\section{E. Analisa dan Perancangan}

Untuk mendapatkan calon perserta didik DIS membutuhkan tahapan untuk dapat mencapai target yang diinginkan yaitu dengan beberapa cara diataranya:

\section{Market Positioning}

Positioning ialah penempatan sebuah pesan dalam benak audience. Dimana suatu image atau citra sebuah pesan mengenai produk, ide, jasa atau gagasan akan diposisikan kebenak konsumen. Duta Islamic School (DIS) Semarangmerupakan sebuah usaha yang bergerak dibidang pendidikan prasekolah. Kurikulum dan program yang diajarkan Duta Islamic School (DIS) Semarang antara lain: Program pembiasaan akhlakul karimah (mengajarkan para siswa didik untuk berperilaku/berakhlak baik), Pengembangan aspek bahasa, seni, kognitif, fisik motorik, life skill dan iptek, Pengenalan huruf hijaiyah (mengajarkan para siswa didik untuk belajar mengenal huruf arab), Pengenalan dan mempraktekan doa - doa harian, wudhu dan sholat, Pengenalan dan pelatihan manasik haji.

Upaya yang dilakukan untuk dapat meningkatkan jumlah siswa siswi di tiap tahunnya dengan cara mempromosikan DIS.Dengan mengguanakan media promosi dan informasi berbasis media cetak (brosur) yang menarik dan variatif sebagai sarana penunjang dalam mempromosikan produk, ide, jasa 
atau gagasan. Olehkarena itu DIS membutuhkan media promosi yang akurat dan mudah disebarluaskan dengan sasaran anak prasekoalah.

\section{Market Objective and Strategi Marketing (Tujuan Pemasaran dan Strategi Pemasaran)}

Didalam sebuah perancangan media informasi dan promosi berbentuk brosur guna meningkatkan jumlah peserta didik DIS ini diharapkan dapat menimbulkan dampak positif dalam hal peningkatan peserta didik DIS. Dengan digunakannya media informasi dan promosi ini diharap juga dapat membuat masyarakat yang belum mengetahui menjadi tahu dan mempercayai anak-anaknya untuk menimba ilmu di DIS. Tujuan dari hasil perancangan promosi dan informaso berbentuk brosur ini untuk menghasilkan desain promosi yang maksimal agar dapat menarik minta calon peserta didik.

\section{Segmentasi Pasar}

Menurut Kotler, segmen pasar terdiri dari kelompok pelanggan yang memiliki seperangkat keinginan yang sama (2005). Tidak ada cara tunggal untuk mensegmentasi pasar. Pemasar harus mencoba sejumlah variabel segmentasi yang berbedabeda, sendiri-sendiri atau bersama-sama, dengan harapan dapat menemukan cara terbaik untuk melihat struktur pasar. Lebih lanjut, Kotler, Bowen dan Makens (2002) menyatakan bahwa segmentasi dapat dilakukan berdasarkan variabelvariabel di bawah ini:

a. Segmentasi Geografis

Segmentasi geografis yaitu meliputi variable wilayah, ukuran kota, kepadatan dan iklim.

b. Segmentasi Demografis

Segmentasi demografis yaitu berdasarkan variable usia, jenis kelamin, penghasilan, pekerjaan, pendidikan, agama dan ras.

c. Segmentasi Psikografis

Segmentasi psikografis mengelompokkan pasar berdasarkan variable kelas sosial, gaya hidup dan kepribadian.

d. Segmentasi Behaviour

Segmentasi behavior dengan variable berdasarkan peristiwa, manfaat, status pemakai, tingkat pemakaian, tahap kesiapan membeli dan sakap terhadap produk.

\section{Desain Layout}

Desain brosur mempunyai ukuran tinggi $20 \mathrm{~cm}$ dan lebar $30 \mathrm{~cm}$. Background pada poster berwarna kuning yang di sertakan juga alamat lengkap dan program unggulan yang yang ditawarkan Duta Islamic School.

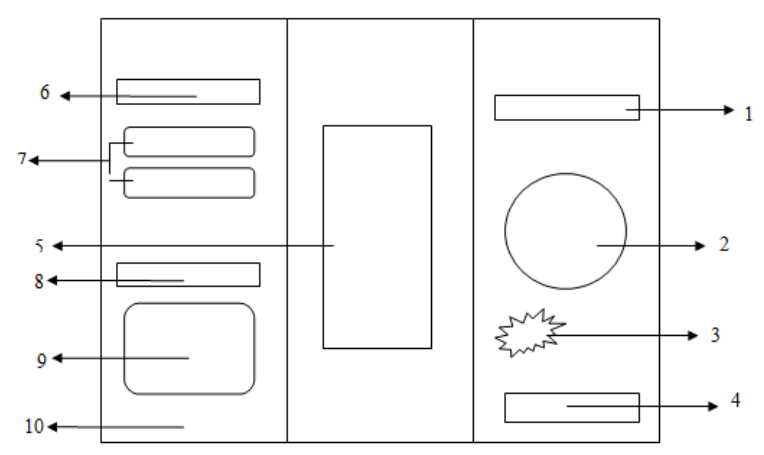

Gbr 2. Konsep Brosur Bagian Luar 


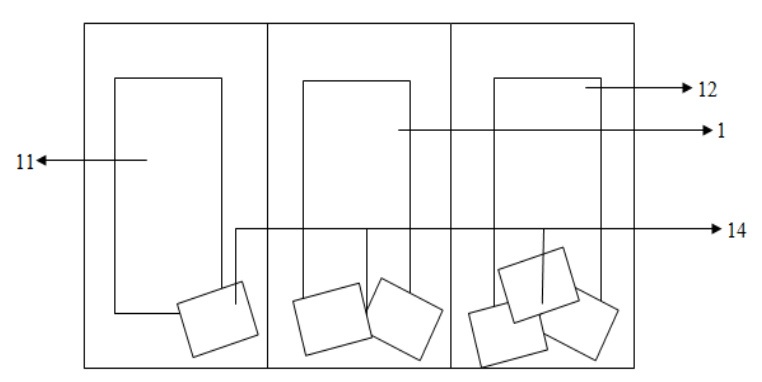

Gbr 3. Konsep Brosur Bagian Dalam

Keterangan :

1. Teks DIS (Duta Islamic School)

Penulis menggunakan font Cooper Black dengan ukuran 40pt pada teks DIS dan 20pt pada teks Duta Islamic School.

2. Logo Playgroup

3. Teks Slogan Playgroup

Penulis menggunakan Cooper Black dengan ukuran 18 pt dengan background explosion untuk penekanan slogantersebut.

4. Alamat Playgroup

Penulis menggunakan font Arial dengan ukuran 12pt agar lebih jelas dan mudah di baca.

5. Denah Lokasi Playgroup.

6. Teks Jadwal Kegiatan

Penulis menggunakan Cooper Black dengan dengan ukuran 24 pt agar lebih jelas dan mudah dibaca.

7. Jadwal Kegiatan peserta didik

8. Teks Syarat Pendaftaran

9. Syarat Pendaftaran

10. Background

11. Program Pendidikan.

12. Fasilitas

13. Program Unggulan

14. Foto Kegiatan

\section{F. Hasil dan Pembahasan}

Hasil akhir media pemasaran dan promosi DIS menggunakan brosur dapat di lihat seperti di bawah ini: 


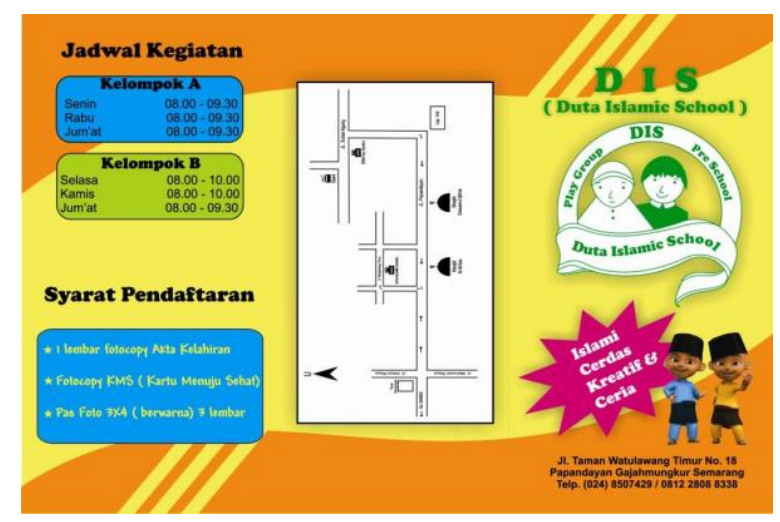

Gbr 4. Hasil Akhir Brosur Bagian Luar

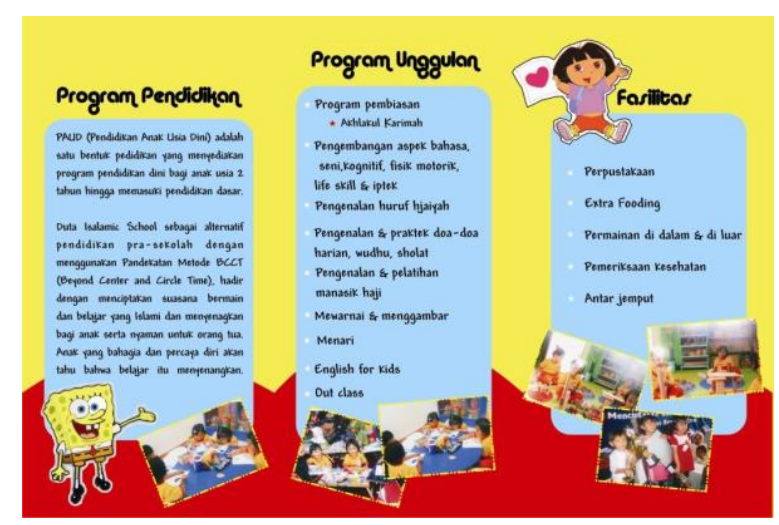

Gbr 5. Hasil Akhir Brosur Bagian Dalam

Gambar di atas adalah hasil final yang sudah melewati beberapa tahapan sebelumnya, Yaitu proses desain Layout dimana desian masih belum siap untuk dicetak masih harus melewati proses revisi. Sehingga sampai pada proses ini naskah serta tata letak merupakan proses akhir untuk siap di produksi.

\section{G. Kesimpulan}

Berdasarkan hasil pembahasan dan analisis yang telah dilakukan, maka dapat ditarik kesimpulan bahwa Pemanfaatan brosur dapat dijadikan sebagai media pemasaran dan promosi yang efektif dan komunikatif sehingga informasi yang diberikan dapat diterima baik oleh target pasar sehingga dapat meningkatkan cakupan wilayah promosi dan meningkatkan jumlah peserta didik pada DIS.

\section{H. Daftar Pustaka}

Andi. 2005, Corel Draw Exercise, Yogyakarta, Penerbit ANDI OFFSET.

Arsyad, Azhar. 2002. "Media Pembelajaran". Jakarta:Raja Grafindo Persada.

Belch, G.E. \& Belch, M.A. (2004) Advertising and Promotion: An Integrated Marketing Communication Perspective. Boston: McGraw Hill-Irwin.

Febriyanto ,Erick , Ainul Mutakin dan Fernanda Setyobudi Armansyah. 2017. Perancangan Desain Brosur Penunjang Informasi dan Promosi pada SMA Pribadi 2. Jurnal Ilmiah SISFOTENIKA Vol. 7, No. 1, Januari 2017

Kotler, P. (2005). Manajemen pemasaran, (Edisi kesebelas), Jakarta: PT. Indeks Kelompok Gramedia. Kotler, P. and K. L. Keller.(2006). Marketing Management.12 ${ }^{\text {th }}$ ed. Upper Saddle River, NJ: PrenticeHall, Inc. 
Kotler, P., Bowen, J., \& Makens, J. (2002). Pemasaran perhotelan dan kepariwisataan, (Edisi Kedua), Jakarta: PT. Prenhallindo.

Mukminin, Amirul \& Cahyani, Meidiana Dwi. 2017. Pengelolaan Pendidikan Anak Usia Dini Pemula di Kecamatan Grabag Kabupaten Purworejo. JNE 3 (1) (2017) 7-52.

Muliawan, Hamri. 2008, Menguasai Corel Draw, Bandung, CV. Yrama Widya.

Soemiarti Patmonodewo, Pendidikan Anak Prasekolah, (Jakarta : PT. Rineka Cipta, 2003), Cet. 2, hlm. 19. 